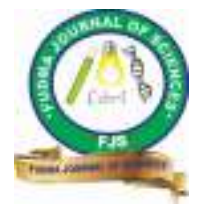

FUDMA Journal of Sciences (FJS)

ISSN online: $2616-1370$

ISSN print: 2645 - 2944

Vol. 4 No. 3, September, 2020, pp $60-71$

DOI: https://doi.org/10.33003/fjs-2020-0403-257

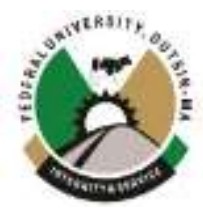

\title{
EXPERIMENTAL AND ANALYTICAL INVESTIGATION OF THE EFFECT OF FIBRE REINFORCED POLYMER ON THE SHEAR STRENGTH OF REINFORCED CONCRETE BEAMS
}

\author{
${ }^{1 *}$ N, Yusuf, ${ }^{2}$ J. M. Kaura, ${ }^{2}$ A. Ocholi, ${ }^{3}$ M. Abbas, ${ }^{2}$ A. Mohammed \\ ${ }^{1}$ Department of Civil Engineering Usmanu Danfodiyo University, Sokoto, Nigeria \\ ${ }^{2}$ Department of Civil Engineering, Ahmadu Bello University, Zaria, Kaduna, Nigeria \\ ${ }^{3}$ Department of Civil Engineering Kaduna Polytechnic, Kaduna, Nigeria \\ *Corresponding Authors' email: nurayusuf07@gmail.com,jmkaura@abu.edu.ng
}

\begin{abstract}
This paper presents the experimental and analytical results of the contribution of carbon fibre reinforced polymer (CFRP) laminates to the shear strength of RC beams. To assess the efficiency of the carbon fibre reinforced polymer (CFRP) laminates on the strengthened specimens, twelve identical beams of crosssectional dimensions $150 \times 150 \times 750 \mathrm{~mm}$ were cast, out of which three are un-strengthened and nine were strengthened with U-wrap strips at $100 \mathrm{~mm}$ away from each support at varying CFRP laminates layers of single, double and triple amounts. The prepared specimens were subjected to a three-point bending test. The results obtained revealed that the CFRP laminate increased the shear strength of the strengthened specimens over the control (un-strengthened) by $35.06 \%, 54.40 \%$ and $69.30 \%$ for single, double and triple layers of CFRP laminate respectively. The experimental results was also compared with the analytical results obtained based on the equation proposed by Khalifa et al., 1998. The analytical results obtained from the equation closely agreed with the experimental results. Therefore, it implies that the CFRP has the potentials of strengthening shear defiant RC beams.
\end{abstract}

Keywords: Shear, Carbon fibre reinforced polymer (CFRP) laminate, RC Beam, Strengthen.

\section{INTRODUCTION}

Many existing reinforced concrete elements are structurally deficient due to a variety of factors that includes poor design, change of use of structure from which it was initially designed for, poor construction method or quality and reduction in, or total loss of the area of the shear reinforcement due to corrosion all accounts for the reduction in strength for the affected RC members Module, (2004). Shear failure of RC beams caused by their brittle nature has been recognized as the most dangerous failure mode, it occurred with no sign of distress Ali et al., (2010). The traditional method for enhancing the strength capacity for the deficient RC members which includes increasing the area of the cross-section and adding additional tension steel reinforcement has proved to be an effective means of increasing strength for the RC members Karzad et al., (2017). But this method of strengthening shows some disadvantages which include adding additional selfweight to the structure, difficult and time-consuming application and lack of durability Triantafillou, (1998). Because of this reasons the use of externally fiber reinforced polymers (FRP) in strengthening affected $\mathrm{RC}$ members became widely acceptable over the traditional technique due to their advantages over the traditional strengthening methods such as ease in application, high strength to weight ratio can take any form or shape, corrosion resistance, etc Baggio et al., (2014);

$$
V_{n}=V_{c}+V_{s}+V_{f}
$$

A research article by Khalifa et al, (1998) showed the impact CFRP has on the shear capacity of the concrete beam through different design processes and techniques. The study presents
Manosr et al., (2013); Pellegrino and Vasic, (2013). "CFRP is a composite material generally consisting of carbon, aramid or glass fibers in a polymeric matrix. Several FRP shear strengthening schemes are available such as; CFRP laminates bonded to the two sides of the beam, strips of CFRP bonded to the two faces at $45^{\circ}$ or $90^{\circ}$ to the horizontal beam axis or a $\mathrm{U}$ wrap or jacket placed along the shear span". For this study, carbon fiber is used and externally application of CFRP oriented at angle $90^{\circ} \mathrm{U}$-wrap strip is adopted for the shear strengthening of reinforced concrete beams.

\section{REVIEW OF CURRENT DESIGN METHODS FOR FRP STRENGTHENING IN SHEAR}

Analytical formulation

Current American Concrete Institute (ACI, 2002 and International Federation for Concrete 2001) design guidelines for strengthening RC beams in shear with CFRP are based on empirical design equations derived by Khalifa et al. (1998) and Triantafillou and Antonopoulos, (2000) respectively. The nominal shear strength ${ }^{\prime} \boldsymbol{V}_{\boldsymbol{n}}{ }^{\prime}$ is calculated by adding individual contributions calculated for the concrete $\boldsymbol{V}_{\boldsymbol{c}}$, internal steel stirrups $^{\prime} \boldsymbol{V}_{\boldsymbol{s}}{ }^{\prime}$, and external FRP composites $\boldsymbol{V}_{\boldsymbol{f}}{ }^{\prime}$ resulting in the general equation.

two equations, dependent on the type of failure of the CFRP sheet used to calculate and suggest that the lowest value is taken. The parameter is dependent on some factors, including 
the stiffness of the sheet, density, number of layers, fibre orientation angle, width, length, adhesive material and the covering method. The two types of methods (Effective FRP stress and Bond Mechanism) will be used to determine the CFRP contribution to the shear strength of the RC beam in this study. The effective FRP stress technique is dependent on the stresses and stress levels within the material, whereas the other mode of failure is based on the connection between the concrete member and the fabric (bond).

\section{Effective CFRP stress}

This design method for calculating $V_{f}$ involves calculating the stress levels in the CFRP. The stresses in the CFRP must be analyzed, including the force required to cause failure. The load is determined by multiplying the ultimate stress and the sheets area that intersects a possible crack. The moment that the CFRP ruptures and tears must be formulated. The article references a literature journal, Triantafillou (1997) which noted that this type of failure is a result of concentrated stresses at certain positions within the sheet, which results in the CFRP rupturing below its ultimate strength capacity. The article observes that this technique doesn't take into consideration the concrete strength or the bonded surface configuration due to limited experimental data.

The design equation that was produced involving the shear capacity of the RC with CFRP externally bonded was,

$$
V_{f}=\frac{A_{f} f_{f e}(\sin \beta+\sin \beta) d_{f}}{s_{f}} \ldots \ldots \ldots
$$

Where;

$d_{f}=$ EffectivedepthofFRPreinforcement.

$\beta=$ Angleoftheprincipalfibreorientation

$A_{f}=$ AreaofFRPshearreinforcement

$f_{f e}=$ Effectivetensilestressinthesheet.

$S_{f}=$ FRPstrip'sspacing.

$V_{f}=$ FRPsheetshearstrength.

Triantafillou, (1997) noted the need for a value of effective strain, which was experimentally determined by calculating $V_{f}$ and varying the shear and CFRP configurations. The experimental results obtained helped to find a relationship between the axial rigidity and the effective strain of the CFRP. The equations found for the effective strain include,

$$
\begin{gathered}
\varepsilon_{f e}=0.0119-0.0205\left(\rho_{f} E_{f}\right)+0.0104\left(\rho_{f} E_{f}\right)^{2} \text { for } 0 \leq \rho_{f} E_{f} \leq 1 G P \ldots \text { (3) } \\
\varepsilon_{f e}=0.00245-0.00065\left(\rho_{f} E_{f}\right) \text { for } \rho_{f} E_{f}>1 G P \ldots \ldots \text { (4) }
\end{gathered}
$$

Where,

$\varepsilon_{f e}=$ EffectiveFRPstrain.

$E_{f}=$ ElasticmodulusofFRP.

$\rho_{f}=$ FRPshearreinforcementratio.

Due to advances in technology and developed progress, Triantafillou, (1997) experimental work has been improved where the effective strain has been slightly modified. The model idea shows that the axial rigidity of the CFRP should not exceed $1.1 \mathrm{GPa}$. Through experimental analysis, a reduction factor has been determined as the ratio of the effective strain to the ultimate strain (R). The ultimate strain is graphed against the axial rigidity of the CFRP. The article established line of best fit in terms of a quadratic where,

$$
R=0.5622\left(\rho_{f} E_{f}\right)^{2}-1.2188\left(\rho_{f} E_{f}\right)+0.778 \leq 0.5 \ldots \ldots(5)
$$

They adopted the limit 'to maintain the shear integrity of the concrete' Therefore the effective strain can be calculated by the reduction factor multiplied by the ultimate strain. That is,

$$
\varepsilon_{f e}=R \varepsilon_{f u}
$$

\section{Bond mechanism}

The study by Khalifa et al, (1998) analyses another type of failure mode, which is dependent on the bond and connection between the concrete surface and the external CFRP reinforcement. They referred to experiments proposed and implemented by Maeda, (1997) which entailed CFRP strips connected to a concrete structure under tensile loading. The experiments were designed to show the relationship between the bonded length and the ultimate tensile strength of the CFRP strip. This was achieved by conducting a number of experiments with a variety of different CFRP sheet stiffness (axial rigidity) and altering the bond length. The remarks of

$$
L_{e}=e^{6.134-0.58 \ln \left(t_{f} E_{f}\right)}
$$

Maeda, (1997) proposed and found that if the bonded length exceeded $100 \mathrm{~mm}$, the tensile force at its ultimate limit within the CFRP is independent of the bonded length. Through experimental data and calculations, Maeda, (1997) was able to formulate an equation based on the bond mechanisms of the CFRP and concrete surface. A number of steps are required to obtain the equation and are based on the CFRP configuration, concrete strength, and load capacity of the CFRP sheet, effective bond length and average bond strength. The effective bond length (Le) is known as the CFRP strip length within the active bonded region of the concrete surface,

Where,

$L_{e}=$ Effectivebondlength. 
$t_{f}=$ CFRPsheetthickness.

$E_{f}=$ ElasticmodulusofCFRP.

The bond strength $(\tau \mathrm{bu})$ was shown through experimental analysis as the thickness of the CFRP sheet multiplied by the elastic modulus and $\mathrm{k}$, an experimental constant,

$$
t_{b u}=K E_{f} t_{f}
$$

Maeda et al., (1997) used a constant concrete strength throughout his experiments and thus to enable the equation to be used with a varying compressive strength, the average bond strength equation is customized to accommodate this problem. The equation is modified to;

$$
t_{b u}=K E_{f} t_{f}\left(\frac{f_{c}^{;}}{42}\right)^{\frac{2}{3}}
$$

The final parameter is the configuration of the CFRP around the concrete surface. The three options Maeda et al., (1997) investigated included completely wrapping the CFRP around the beam, a U shape and the sheet bonded only to the sides of the beam. An effective width of the CFRP is used 'once a shear crack develops, only that portion of FRP extending past the crack by the effective bonded length will be capable of carrying shear'. Therefore the three equations were established depending on the CFRP configuration, $w_{f e}=d_{f}$ (completely wrapped beam)...(10)

$w_{f e}=d_{f}-2 L_{e}$ (sides wrap).

$$
w_{f e}=d_{f}-L_{e}(\mathrm{U} \text { shape wrap }) .
$$

$V_{f}$ Was established by taking into account all the factors and parameters above with the design equation proposed by Maeda et al., (1997) as shown in equation (2.13). The limitation based on this method is that it doesn't take into consideration the angle of the CFRP orientation.

Where;

$$
V_{f}=\frac{2 L_{e} w_{f} t_{b u} w_{f e}}{s_{f}} .
$$

$w_{f}=$ WidthofFRPstrip.

$w_{f e}=$ EffectivewidthofCFRPsheet.

$S_{f}=$ CFRPstrip'sspacing.

$L_{e}=$ Effectivebondlength.

$t_{b u}=$ Averagebondstrength.

$d_{f}=$ EffectivedepthoftheFRP.

Using the shear parameters $\emptyset=0.85$ and $\emptyset=0.7$ for concrete and steel shear contributions and CFRP contribution respectively thus the total shear strength will be calculated as;

$$
V_{n}=0.85\left(V_{c}+V_{s}\right)+0.7 V_{f} \ldots . .
$$

\section{EXPERIMENTAL PROGRAM}

\section{Materials}

All specimens for this study are casted using ordinary Portland cement confirming to BS EN 197-1 and concrete mix confirming to BS EN 206-1 with mean compressive cubes strength of $31.7 \mathrm{~N} / \mathrm{mm}^{2}$ at the age of 28 days. The mix design was in accordance to BS EN 206-1. High yield steel is used as the reinforcing bars with its properties shown in table 1

confirming to BS EN 10080.The strengthening material used is a uni-directional woven CFRP fabric and the bonding agent used is a two component epoxy resin (Araldite GY). The mechanical properties of these materials were provided according to the test carried out by the manufacturers, Beijing Fiber Glass Company and Super floors Epoxy, as shown in table 2 and 3 respectively.

Table 1.0 Material properties of reinforcing steel

\begin{tabular}{ccc}
\hline $\begin{array}{c}\text { Diameter } \\
(\mathbf{m m})\end{array}$ & Area $\left(\mathbf{m m}^{\mathbf{2}}\right)$ & $\begin{array}{c}\text { Yield strength } \\
\left(\mathbf{N} / \mathbf{m m}^{2}\right)\end{array}$ \\
\hline $\mathbf{6}$ & 28.28 & 261 \\
$\mathbf{8}$ & 50.27 & 335 \\
$\mathbf{1 0}$ & 78.55 & 464 \\
\hline \hline
\end{tabular}


Table 2.0 Properties of fibreCXS-200

\begin{tabular}{ccc}
\hline \hline S/N & Physical properties & Value \\
\hline $\mathbf{1}$ & Tensile strength & $3400 \mathrm{MPa}$ \\
$\mathbf{2}$ & Modulus of Elasticity & $240 \mathrm{MPa}$ \\
$\mathbf{3}$ & Density & $1.76 \mathrm{~g} / \mathrm{cm}^{3}$ \\
$\mathbf{4}$ & Thickness & $0.11 \mathrm{~mm}$ \\
$\mathbf{5}$ & Ultimate strain & $1.7 \%$ \\
$\mathbf{6}$ & Width & $200 \mathrm{~mm}$ \\
\hline \hline
\end{tabular}

Table 3.0 Properties of epoxy resin

\begin{tabular}{ccc}
\hline \hline S/N & Physical properties & Values \\
\hline $\mathbf{1}$ & Mix ratio & $2: 1$ \\
$\mathbf{2}$ & Colour & Brown \\
$\mathbf{3}$ & Pot Life @ 30 $30^{\circ} \mathrm{C}$ & $\pm 30-40 \mathrm{mins}$. \\
$\mathbf{4}$ & Cure time & 7 days \\
$\mathbf{5}$ & Tensile strength, 7 days & $10.4 \mathrm{~N} / \mathrm{mm}^{2}$ \\
$\mathbf{6}$ & Compressive strength, 7 days & $60 \mathrm{~N} / \mathrm{mm}^{2}$ \\
$\mathbf{7}$ & Flexural Strength & $28.1 \mathrm{~N} / \mathrm{mm}^{2}$ \\
\hline \hline
\end{tabular}

\section{Details of specimens}

A total number of nine beams with a rectangular cross sectional dimension of $150 \times 150 \times 750 \mathrm{~mm}$ were fabricated, all according to the specifications of Eurocode2. The beams to be strengthened are designed to be weak in shear as compared to the reference control specimens. Two numbers of $8 \mathrm{~mm}$ diameter bars are provided as compression reinforcement and two $10 \mathrm{~mm}$ diameter bars are provided as the tension

reinforcement for all the specimens. Two legged steel stirrups of $6 \mathrm{~mm}$ diameter are provided at $100 \mathrm{~mm}$ centers for the reference control beams and same diameter steel stirrups at $125 \mathrm{~mm}$ centers for the strengthened specimens to act more deficient in shear than the un-strengthened reference control beams. The structural details for the reference control specimen and strengthened specimen is provided in Figure 1 and 2 respectively.

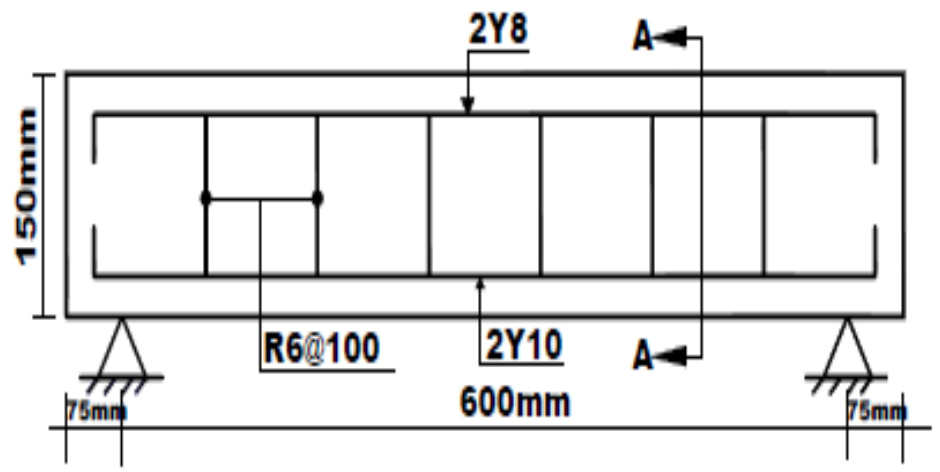

SECTION A.A

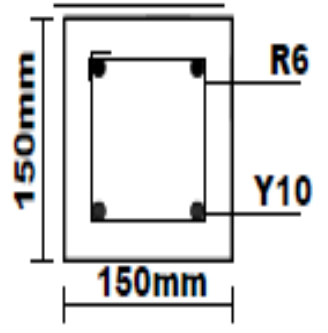

Figure 1: Structural detail of reference control beam 

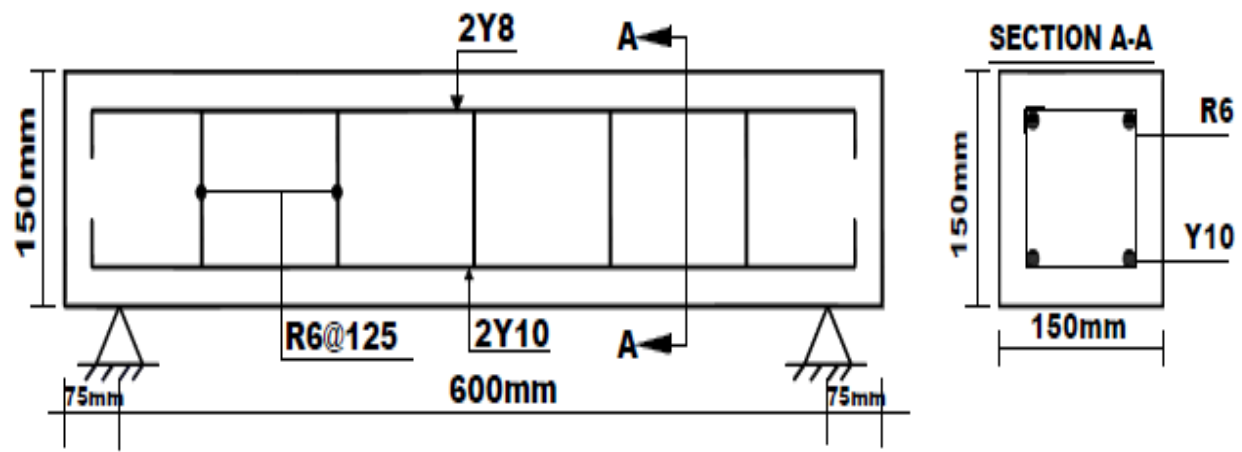

Figure 2: Structural detail of CFRP Strengthened beam

\section{Strengthening of Specimens}

The CFRP sheets/laminates were cuts to the required size and lengths and are externally bonded in U-wrap (strips) at an angle of approximately $90^{\circ}$ to the longitudinal axis of the beam in various amount ranging from single U-wrap to triple U-wrap strips except two out of the fabricated specimens marked as CB01 and CB02 were not externally bonded and served as the reference control specimens. Prior to the strengthening, the beams surfaces to be bonded with CFRP were cleaned of loose particles and the edges were properly smoothed to provide a sound U-wrap bonding between the concrete surfaces and the CFRP laminates. Figure 3 and Table 4 shows the strengthening scheme and summary respectively.

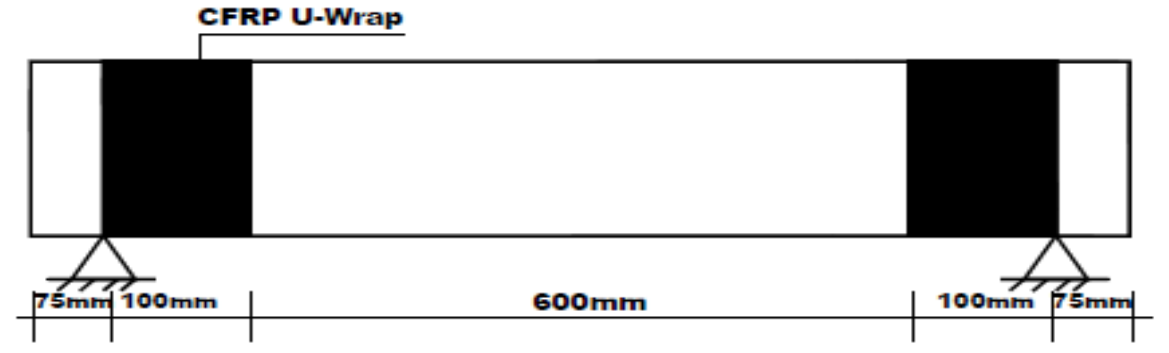

Figure 3 Strengthening scheme

Table 4.0 Strengthening summary

\begin{tabular}{ccccc}
\hline \hline Beam ID & U-wrap layers & Thickness $(\mathbf{m m})$ & Fiber orientation & Test method \\
\hline CB01 & - & - & - & 3 Point \\
CB02 & - & - & - & 3 Point \\
SL01 & 1 & 0.11 & $90^{0}$ & 3 Point \\
SL02 & 1 & 0.11 & $90^{0}$ & 3 Point \\
DL01 & 2 & 0.22 & $90^{0}$ & 3 Point \\
DL02 & 2 & 0.22 & $90^{0}$ & 3 Point \\
TL01 & 3 & 0.33 & $90^{0}$ & 3 Point \\
TL02 & 3 & 0.33 & $90^{0}$ & 3 Point \\
\hline
\end{tabular}

\section{Test set-up}

All the beams were subjected to three point bending test and simply supported with a pinned support at $75 \mathrm{~mm}$ away from the edge of each beam. The load is applied at center of the beam $(\mathrm{L} / 2)$ using a hydraulic jack and the intensity of the load is measured using a load cell beside the hydraulic jack. The mid span deflection is measured with dial gage placed at exactly below the loading point at the center of the beam. The experimental set up is shown in Plate 1.0 below. 


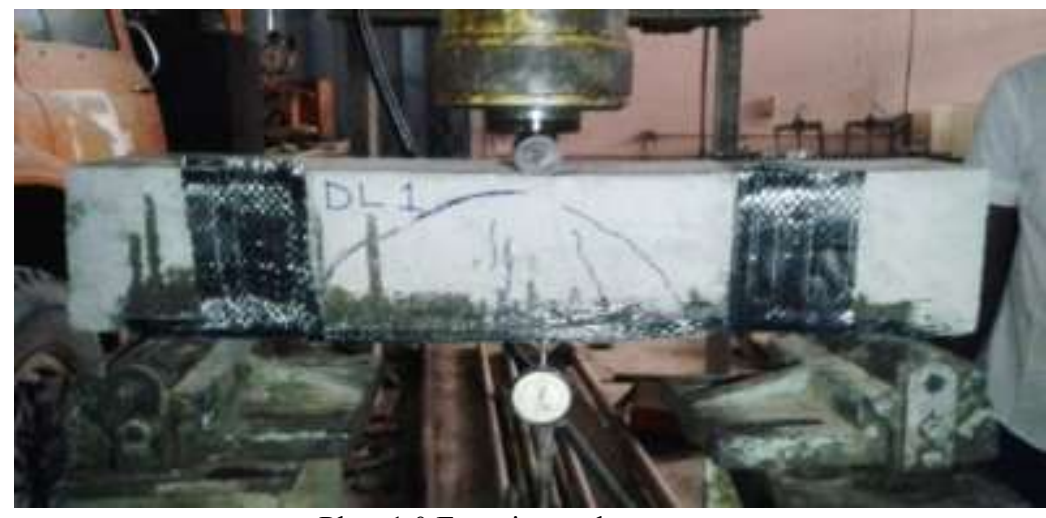

Plate 1.0 Experimental setup

\section{Compressive strength of concrete}

\subsection{Results and Discussion}

The concrete used for all the test beams is grade M25. The mix design was based on BS EN 206-1 [13]. Fifteen test cubes were prepared from the mix and tested at the age of 1 day, 3 days, 7 days, 21 days and 28 days and the results are presented in Table 4.0 .

Table 4.0: Compressive strength test result for the considered mix ratio

\begin{tabular}{cccccc}
\hline \hline $\begin{array}{c}\text { Compressive strength } \\
\left(\mathbf{N} / \mathbf{m m}^{\mathbf{2}}\right)\end{array}$ & 1 Day & 3 Days & 7 Days & 21 Days & 28 Days \\
\hline Average of 3 cubes & 5.4 & 12.5 & 20.9 & 22.7 & 31.7 \\
\hline \hline
\end{tabular}

\section{Specimen results}

The test results for nine numbers of beams including the control specimens are summarized in Table 5.0. The ultimate shear load obtained in the experiment together with the theoretical values obtained from the model developed by Khalifa et al., (1998) all presented. It was observed that the results obtained from the model were closely related to that obtained from the experimental results, but that of the experimental is higher than the predicted results obtained from the model. Figure 4-7 clearly shows the increase in the load capacity of the beams strengthened with FRP U-wrap for various amounts varying from single to triple layers U-wrap and for the load-deflection curves average values for the control and strengthened specimens were used.

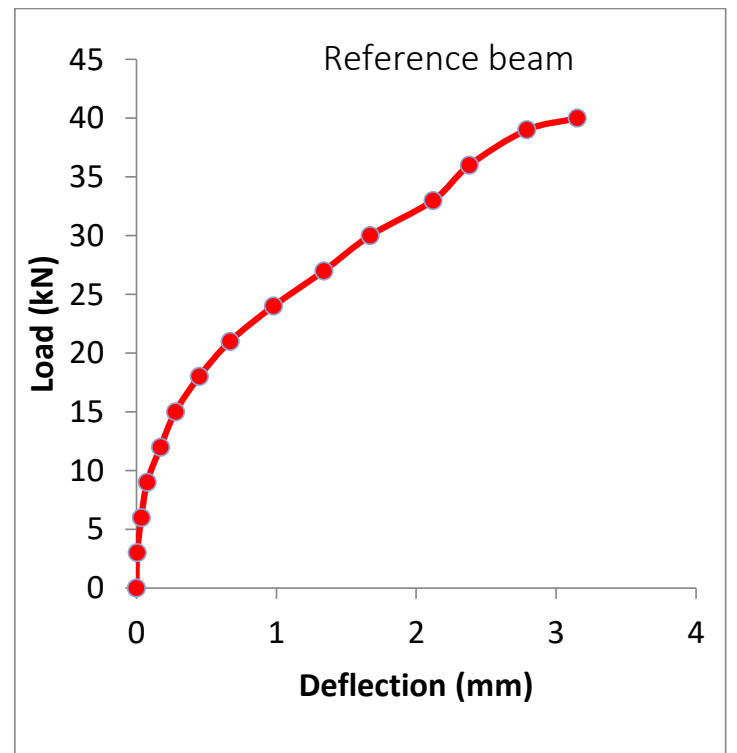

Figure 4.0 Load-deflection curve for control beam (reference beam). 


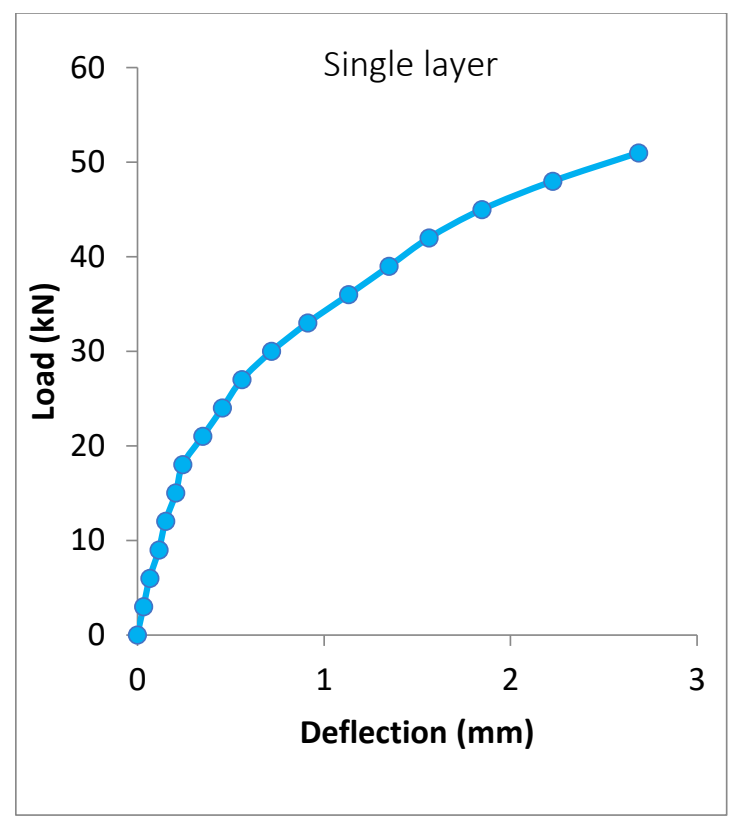

Figure 5.0 Load-deflection curve for single layer beam.

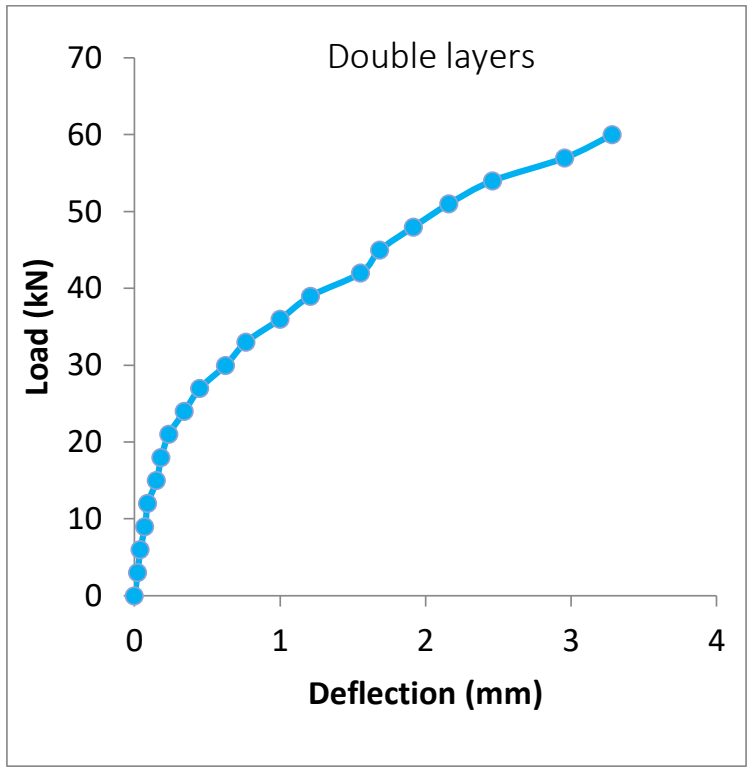

Figure 6.0 Load-deflection curve for double layers beams 


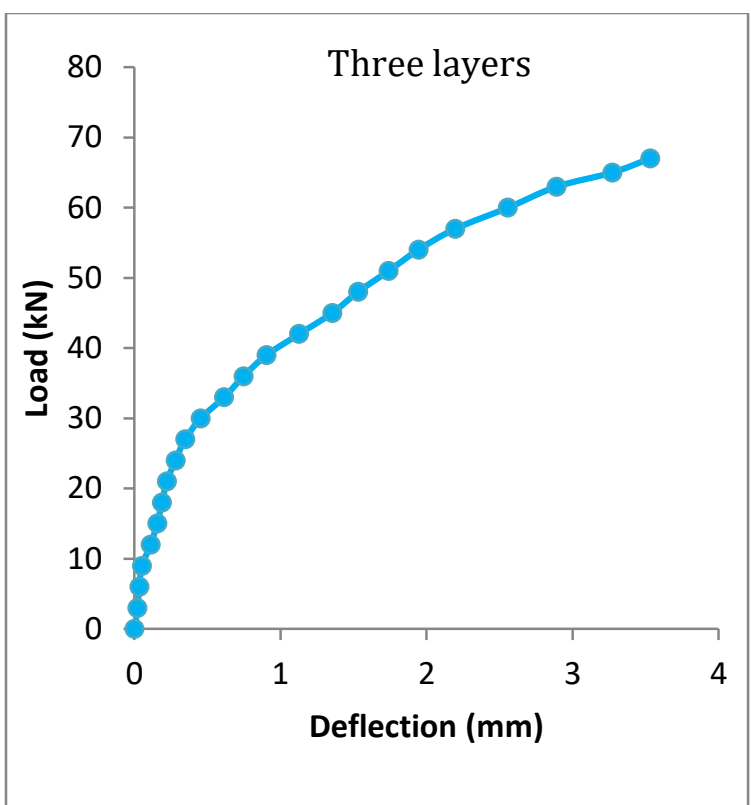

Figure 7.0 Load-deflection curve for three layers beam 
Table 4.1 Experimental and Theoretical Results

\begin{tabular}{|c|c|c|c|c|c|c|c|c|}
\hline Beam ID & $\begin{array}{l}\text { Number of } \\
\text { FRP layers } \\
\text { (U-wrap) }\end{array}$ & $\begin{array}{c}\text { Experimental } \\
\text { shear strength(KN) }\end{array}$ & $\begin{array}{c}\text { Theoretical FRP } \\
\text { shear strength } \\
V_{f}(\mathrm{KN})\end{array}$ & $\begin{array}{c}\text { Theoretical total } \\
\text { shear strength(KN) }\end{array}$ & $\begin{array}{c}\text { Experimental \% } \\
\text { increase as compared } \\
\text { with control beam }\end{array}$ & $\begin{array}{l}\text { Analytical \% } \\
\text { increase }\end{array}$ & $\frac{V_{u}(\text { expt. })}{V_{t}(\text { theo. })}$ & Failure mode \\
\hline$\overline{\mathrm{RB}}$ & - & 38 & - & 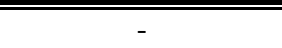 & - & - & & Shear -Flexure \\
\hline SL01 & 1 & 49 & 22.9 & 43.57 & 28.9 & 58.21 & 1.13 & Shear -Flexure \\
\hline SL02 & 1 & 52 & 22.9 & 43.57 & 36.8 & 58.21 & 1.19 & Shear \\
\hline SL03 & 1 & 53 & 22.9 & 43.57 & 39.5 & 58.21 & 1.22 & Debonding \\
\hline DL01 & 2 & 57 & 39.48 & 55.18 & 50.0 & 100.35 & 1.03 & Shear \\
\hline DL02 & 2 & 60 & 39.48 & 55.18 & 57.9 & 100.35 & 1.08 & Concrete crushing \\
\hline DL03 & 2 & 59 & 39.48 & 55.18 & 55.3 & 100.35 & 1.06 & Debonding \\
\hline TL01 & 3 & 64 & 40.35 & 55.90 & 68.4 & 102.60 & 1.15 & Shear \\
\hline TL02 & 3 & 63 & 40.35 & 55.90 & 65.8 & 102.60 & 1.23 & Debonding \\
\hline TL03 & 3 & 66 & 40.35 & 55.90 & 73.7 & 102.60 & 1.18 & Debonding \\
\hline
\end{tabular}




\section{Deformation behavior}

The test results for the control beams show that the beams failed in shear and flexure, which means that the shear capacity has been reached to maximum. The failure modes for the beams strengthened with one layer FRP U-wrap show that the beams mostly failed in shear at an angle approximately $45^{\circ}$ that extend up to the point of contact between the beam and the loading roller, debonding of the FRP laminates occurs at the tip point of the U-wrap. Same deformation behavior was accompanied for the double layers FRP U-wrap beams but at a higher loading capacity than that of the single layer FRP Uwrap and this time around concrete crushing at the compression zone was also observed. For the three layers FRP U-wrap specimens, it was observed that the increase in the ultimate load was just slightly above that of the double layers FRP U-wrap and the beam failed due to shear at angle of $45^{\circ}$ and debonding of the FRP laminate at the tip of the U-wrap. In general it was observed that at a point in time increasing the amount or number of CFRP layers will reached a point in which it will not show any significant effect to the strength increase as it was observed from this research for the double and triple layers of the FRP materials. The crack pattern and failure modes for the strengthened beams are shown in plate 26.

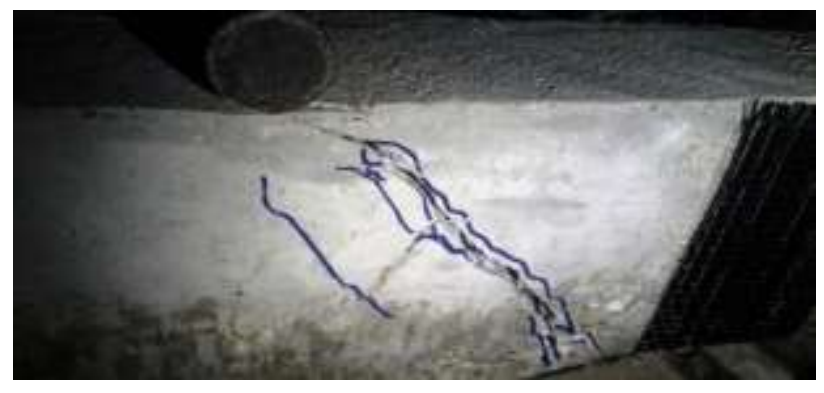

Plate 2: Crack pattern for Single U-wrap beam 1

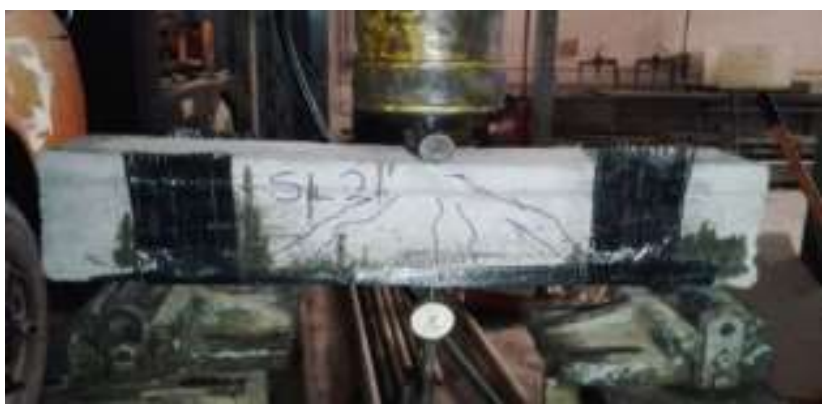

Plate 3: Crack pattern for Single U-wrap beam 2 


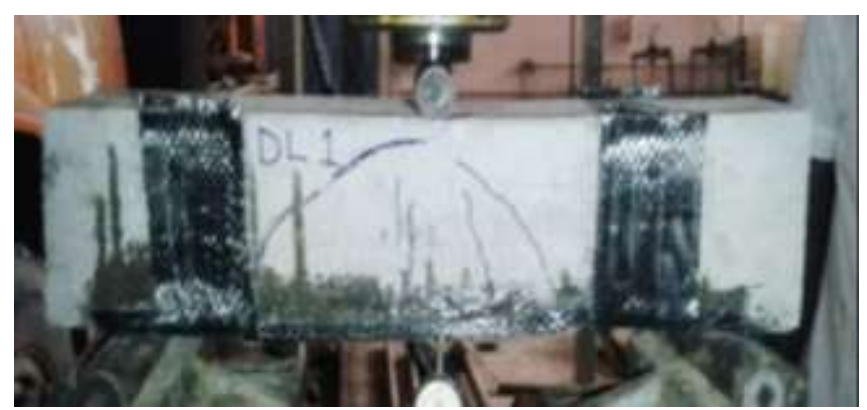

Plate 4: Crack pattern for double U-wrap beam 1

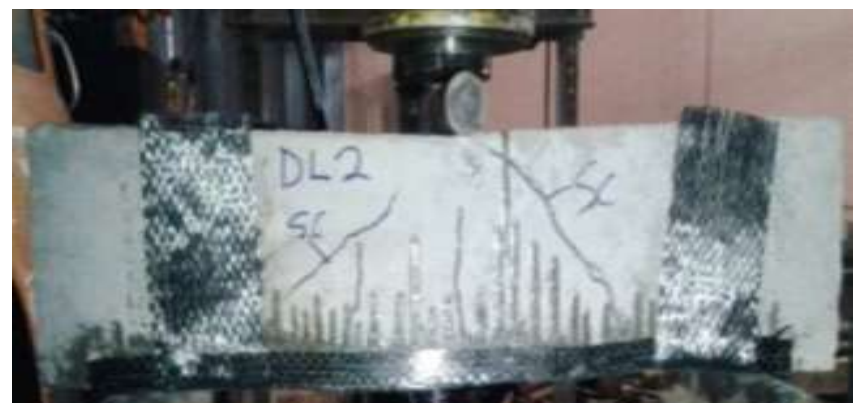

Plate 5: Crack pattern for double U-wrap beam 2

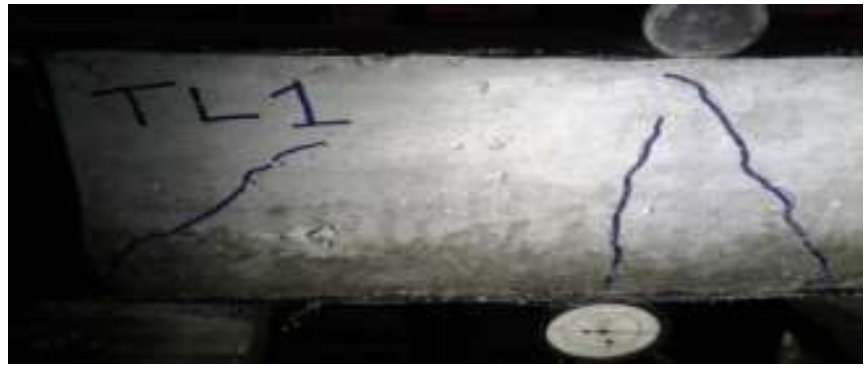

Plate 6: Crack pattern for three U-wrap beam1

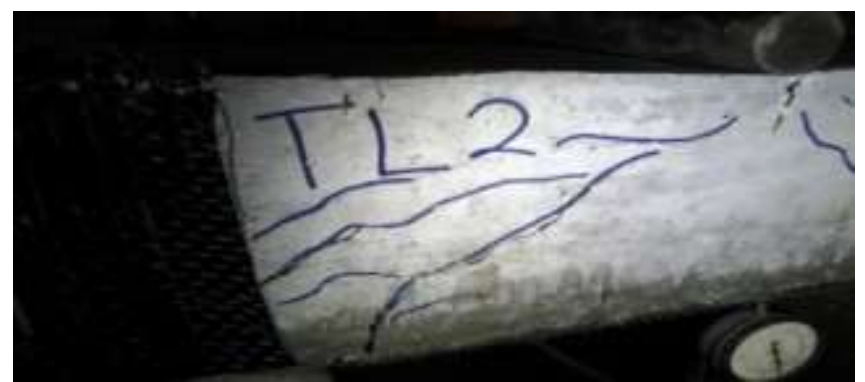

Plate 6: Crack pattern for three U-wrap beam 2

\section{CONCLUSION}

The present research study focused on performing a comprehensive experimental and theoretical work to explore the efficiency of CFRP composites as external shear reinforcement in various amount. The results indicated that

1- The ultimate shear strength load carrying capacity of R.C beams was observed to increase with the increase in number of CFRP layer from 1-3 layers significantly, but more effective for the single and double layers U-wraps. significant increase in shear strength could be achieved by the application of CFRP to concrete beams deficient in shear capacity when U-wrap is properly applied over the shear span. From the experimental and theoretical research work carried out the following conclusions are drawn.

2- The use of the U-wrap bonded CFRP sheets in strengthening reinforced concrete beams reduces the deflection and increases the load carrying capacity and it was noticed that cracks do occur are smaller 
and more evenly distributed than the control specimens.

3- From the study it was noticed that for an optimum shear strengthening a minimum of two layers for this particular CFRP and matrix used should be adopted to obtain a desirable increase in strength of shear deficient beams.

4- The Experimental values of the ultimate shear strength of CFRP U-wrapped R.C beams are more than the theoretical values predicted from the model.

\section{REFERENCES}

Ali, N., Samad, A. A. A., Jayaprakash, J., Iesa, W., \&Alferjani, M. (2010). Study on Shear Strengthening of RC Continuous Beams with Different CFRP Wrapping Schemes. International Journal of Integrated Engineering, 2(2).

Baggio, D., Soudki, K., \& Noel, M. (2014).Strengthening of shear critical RC beams with various FRP systems. Construction and Building Materials, 66, 634-644.

BS EN.1008, (2002). Mixing Water for Concrete-Specification for Sampling, Testing, and Assessing the Suitability of Water, Including Water Recovered From Processes in the Concrete Industry, as Mixing Water for Concrete. British Standards Institution, London.

BS EN.10080, (2005). Steel for the reinforcement of concrete: weldable reinforcing steel: general. Brussels: Central Secretariat.

BS EN.206-1, (2000). Concrete-Part 1: Specification, performance, production and conformity.British Standards Institution.

BS EN1992-1: Design of concrete structures Part $1-1-$ General rules and rules for buildings -Part 1-2 - General rules - Structural file design. British Standard Institution, 2004.

BS EN 197-1, (2011). Cement. Composition, specifications and conformity criteria for common cements.

Karzad, A. S., Al Toubat, S., Maalej, M., \&Estephane, P. (2017). Repair of reinforced concrete beams using carbon fiber reinforced polymer. Paper presented at the MATEC Web of Conferences.

Khalifa, A., Gold, W. J., Nanni, A., \& MI, A. A. (1998).Contribution of externally bonded FRP to shear capacity of RC flexural members.Journal of composites for construction, 2(4), 195-202.
Maeda, T. (1997).A study on bond mechanism of carbon fiber sheet. FRPTCS3, 1, 279-286.

Manosr, G., Katakalos, K., Theofanous, M., Kozikopoulos, E., \& Upgrade, S. (2013). Experimental And Numerical Investigation Of Rectangular R/C Beams Retrofitted Against Shear Utilizing CFRP Strips. No. June, 12-14.

Module, I. E. (2004).An Introduction to FRP Strengthening of Concrete Structures.Prepared by ISIS Canada.A Canadian Network of Centres of Excellence.

Pellegrino, C., \& Vasic, M. (2013). Assessment of design procedures for the use of externally bonded FRP composites in shear strengthening of reinforced concrete beams. Composites Part B: Engineering, 45(1), 727-741.

Triantafillou, T. (1997). Shear strengthening of concrete members using composites. Paper presented at the Third International Symposium on Non-Metallic (FRP) Reinforcement for Concrete Structures.

Triantafillou, T. C. (1998). Shear strengthening of reinforced concrete beams using epoxy-bonded FRP composites. ACI structural journal, 95, 107-115.

Triantafillou, T. C., \& Antonopoulos, C. P. (2000). Design of concrete flexural members strengthened in shear with FRP. Journal of composites for construction, 4(4), 198-205. 